\title{
Clinical and virological findings in the ongoing outbreak of West Nile virus Livenza strain in northern Italy, July to September 2012
}

L Barzon ${ }^{1,2}$, M Pacenti $^{2}$, E Franchin ${ }^{1,2}$, T Martello $^{2}$, E Lavezzo ${ }^{1}$, L Squarzon ${ }^{1}$, S Toppo ${ }^{1}$, F Fiorin ${ }^{3}$, G Marchiori ${ }^{3}$, G P Scotton ${ }^{4}$, F

Russo ${ }^{5}, M$ Cattai $^{2}$, R Cusinato ${ }^{2}$, G Palù (giorgio.palu@unipd.it) ${ }^{1,2}$

1. Department of Molecular Medicine, University of Padova, Padova, Italy

2. Regional Reference Laboratory for Infectious Diseases, Microbiology and Virology Unit, Padova University Hospital, Padova, Italy

3. Department of Transfusion Medicine, Venetian Area, Venice, Italy

4. Division of Infectious Diseases, Treviso City Hospital, Treviso, Italy

5. Department of Public Health and Screening, Veneto Region, Venice, Italy

Citation style for this article:

Barzon L, Pacenti M, Franchin E, Martello T, Lavezzo E, Squarzon L, Toppo S, Fiorin F, Marchiori G, Scotton GP, Russo F, Cattai M, Cusinato R, Palù G. Clinical and virological findings in the ongoing outbreak of West Nile virus Livenza strain in northern Italy, July to September 2012. Euro Surveill. 2012;17(36):pii=20260.

Available online: http://www.eurosurveillance.org/ViewArticle.aspx?Articleld=20260

In July-September 2012, one month earlier than in previous years, 13 confirmed human cases of West Nile virus infection were diagnosed in northern Italy, including five with neuroinvasive disease, three with West Nile fever, and five West Nile virus (WNV)positive blood donors. In nine cases, the presence of the WNV lineage 1a Livenza strain, characterised in 2011, was ascertained. Symptomatic patients had prolonged viruria with high viral load.

In 2012, West Nile virus (WNV) infection has become a concern for many public health experts. Earlier occurrence in this year of an increased number of human cases has been reported by European countries to the European Centre for Disease Prevention and Control (ECDC) [1]. Moreover in the United States, over 1,000 WNV infection cases have been reported to the Centers for Disease Control and Prevention (CDC), the highest number for the period, since WNV was first detected in the country in 1999 [2].

We recently reported the case of a WNV ribonucleic acid (RNA)-positive blood donation identified in northern Italy in July 2012, which suggested circulation of WNV one month earlier than in previous years [3]. Partial sequencing of the WNV RNA (GenBank accession numbers: JX417422 and JX470578) demonstrated identity with the genome of a lineage 1a WNV strain, called Livenza strain, which had been identified in the same area in 2011 (WNV-Livenza/2011 strain) and which was divergent from the strain responsible for the 2008-09 outbreak in northern Italy [3]. We report here an update on the surveillance activity for WNV in northern Italy, which confirms the feared earlier occurrence of human cases and the spread of the Livenza strain. We also describe clinical and virological findings in patients with WNV infection and the rapid public health interventions that were undertaken in the affected areas.

\section{Surveillance activities and results}

In Italy, surveillance activities for human WNV neuroinvasive disease (WNND) are defined annually by the National surveillance programme [4]. In addition, in the Veneto region, special surveillance for West Nile fever has been implemented since 2010. According to the protocol, from 15 June to 30 November, patients with fever over $38.5^{\circ} \mathrm{C}$ and absence of concomitant diseases which could account for the febrile illness, are investigated as possible cases of WNV infection and referred to the regional reference laboratory for confirmation, as reported $[5,6]$. Confirmed cases of WNV disease are immediately notified from local public health departments to the regional authorities, which report cases to the Ministry of Health. The case definition of WNND and West Nile fever is as defined by the European Union [7]. Since 2012, detection of WNV RNA in urine has been included among the laboratory confirmation criteria. In the Veneto region, according to the 2012 national directives, nucleic acid amplification testing (NAAT) for screening of tissue and organ donations is carried out in the period between 15 July and 30 November in all the regional territory, while screening of blood donations is carried out during the same period in the provinces where human cases of WNND were identified in 2011, i.e. Venice, Treviso, and Belluno provinces.

By 3 September 2012, 13 confirmed cases of WNV infection, including the first previously reported case in July, have been diagnosed in the Veneto region. The 13 cases had symptom onset between 15 July and 24 August, and eight were male. Cases had an age range of 49 to 87 years. The presence of WNV lineage 1 was demonstrated in 12 cases with detectable WNV RNA by specific real-time reverse transcription polymerase chain reaction (RT-PCR) assays, as previously described [5]. For nine cases who had a relatively high viral load in blood or urine, sequencing of WNV RNA 
was successful and ascertained that all these cases were infected with the WNV Livenza strain (Table). For one of these cases, the virus was isolated in cell culture and fully sequenced (GenBank accession number: JX556213). Genome sequence analysis demonstrated, that compared with the full genome sequence of the WNV-Livenza/2011 strain (GenBank accession number: JQ928174) [8], the sequence of the isolated virus harboured two non-synonymous substitutions, resulting in a Val113lle amino acid mutation in the capsid protein and a Val45Ile mutation in the non-structural protein 5 (NS5). Eight synonymous nucleotide changes were additionally observed. The strain of the isolated virus was named WNV Livenza/2012/31.1 strain, with 31 representing the week number and one the sequential number of cases of the week.

\section{Findings in blood donors}

The first case of WNV infection in Italy in 2012, as already described [3], was identified by NAAT screening of blood donors in Venice province on 15 July. Further six positive blood donations were later detected among donors who resided in nearby areas to the first case (Figure), two of these as recently as September 2012. So far, laboratory and follow-up data are available for the first five infected blood donors detected, who are therefore included among the 13 total cases described in this communication. The most common symptom reported among the five blood donors was asthenia that occurred one to five days after donation. One donor, however, reported asthenia only at follow-up visits after retrospectively recalling having this symptom two days before donation. All but one donor were WNV IgM positive at the time of donation and developed IgG antibodies within the following week. In the urine of three donors, up to 5,000 copies/mL of WNV RNA were detectable, and this persisted for up to six days longer than in blood (Table). WNV RNA detection in urine was performed by using two different real-time RT-PCR methods, respectively targeting WNV lineage 1 [9], and both WNV lineage 1 and lineage 2 [10] on total nucleic acids purified from $1 \mathrm{~mL}$ urine, by using the NucliSENS EasyMAG system (bioMérieux SA, Marcy l’Etoile, France).

\section{Findings in patients}

Five cases of WNND and three of West Nile fever were confirmed (Table). A further probable case of WNND and two probable cases of West Nile fever are currently under investigation. Symptoms in patients with WNND were not severe and clinical improvement was observed in most patients. A common laboratory finding in patients with WNND or West Nile fever was detection of WNV RNA at high load (up to 100,000 copies $/ \mathrm{mL}$ ) in urine, and its persistence (over 30 days in one case) for a longer time than in blood and in the cerebrospinal fluid (CSF), even in the presence of WNV IgG antibodies. Of the eight patients, infection by WNV Livenza strain was confirmed in six. Five of these patients were resident in Venice province, in the area surrounding the Livenza river, and one in Treviso province, near the
Piave river, in an area where, in 2011, a different WNV lineage 1a strain, called Piave strain, was identified in a patient and fully sequenced [8] and WNV lineage 2 was detected by veterinary surveillance [11].

\section{Rapid public health interventions}

In areas where human cases of WNV infection occurred and in neighbouring municipalities, measures for control of Culex mosquitoes, which are the prime vector for WNV transmission, were immediately implemented in accordance with the regional intervention protocol. In addition, information leaflets about WNV fever and effective protection against mosquito bites were disseminated to the population in public places and on the websites of regional and local health units.

\section{Discussion}

This report describes 13 confirmed human cases of WNV infection diagnosed in north-eastern Italy between July and September 2012. Cases occurred one month earlier than previously reported, and this could be attributable to the ongoing very hot summer season, probably responsible for the very high mosquito density, that has been observed in the affected areas. In nine cases, for whom viral RNA sequencing was successful, infection with the recently identified WNV Livenza strain was demonstrated. The new WNV strain did not appear particularly virulent and lethal, since cases had no severe symptoms and positive outcome. However, due to their small number, the virulence and lethality of the new WNV lineage 1a Livenza strain remains to be defined. To this aim, studies on animal models will be conducted with the viral isolate. The Livenza strain is classified within the Mediterranean cluster, but has several novel amino acid substitutions in non-structural proteins that are not present in other European and non-European strains, that could be relevant for virus transmissibility and neuroinvasive potential [8].

Clinical evaluation demonstrated variability of symptoms among patients, including retinitis, meningitis, gastrointestinal symptoms, respiratory failure and lower limb neuritis, besides fever, headache, asthenia, arthralgia, and myalgia. Asthenia was a common symptom in blood donors and one donor only recalled it in retrospect. Thus, asking blood donors about this symptom before donation, in areas where WNV is endemic, could help to recognise potentially infected individuals. To this end, interviews are useful and one of our patients with WN fever was identified by interview at the visit for blood donation. Detection of WNV RNA in urine was very useful for early laboratory diagnosis of WNV infection, since in some patients viral RNA was detectable only in urine and not in blood. Remarkably, patients with WNND or West Nile fever had WNV shedding at high load in urine for several days after symptom onset and seroconversion, and even after the appearance of IgG antibodies, when viral RNA was no longer detectable in blood or CSF. In addition, 


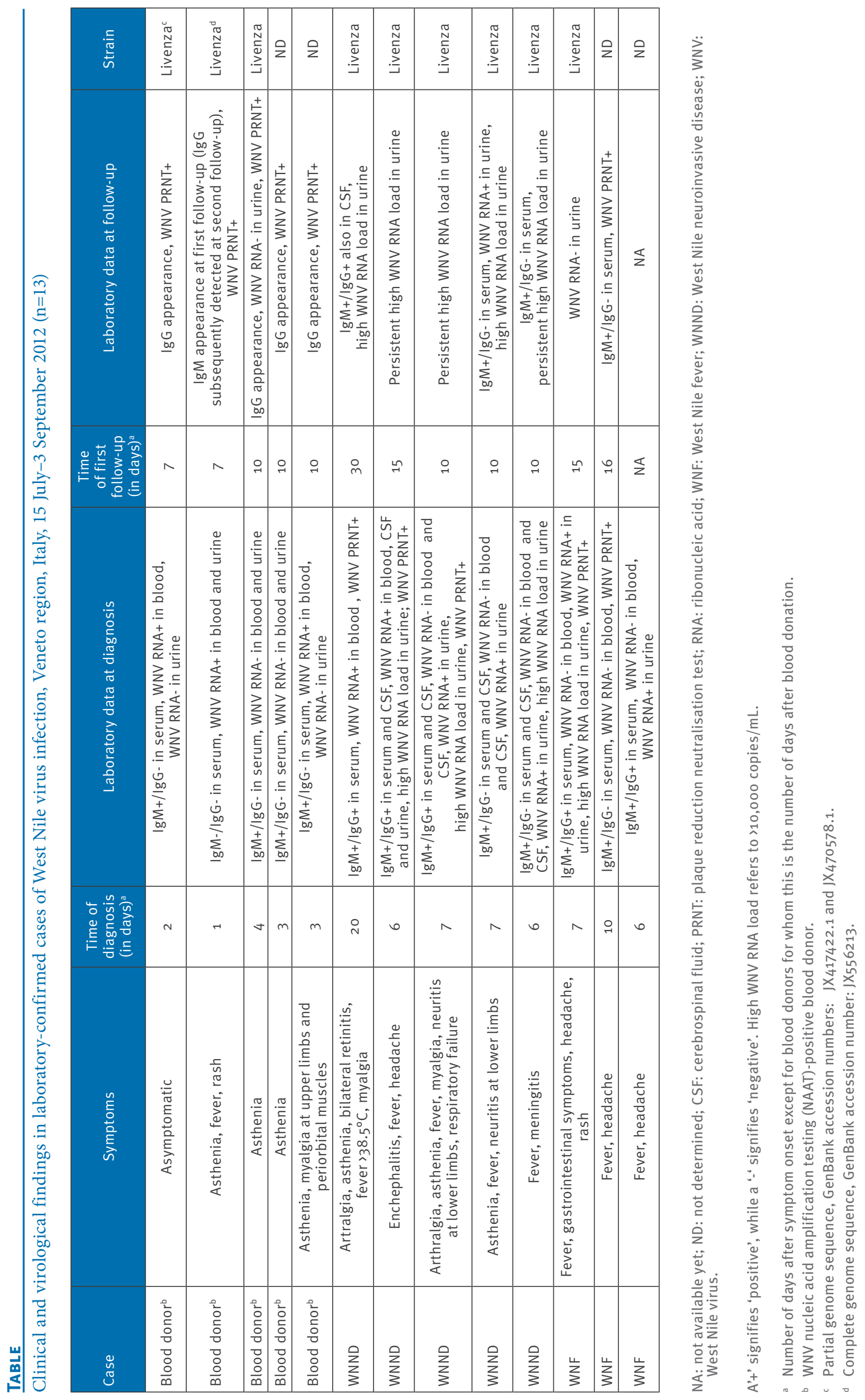


Origin of confirmed human cases of West Nile virus infection, Veneto region, Italy, 15 July-3 September 2012 (n=13)

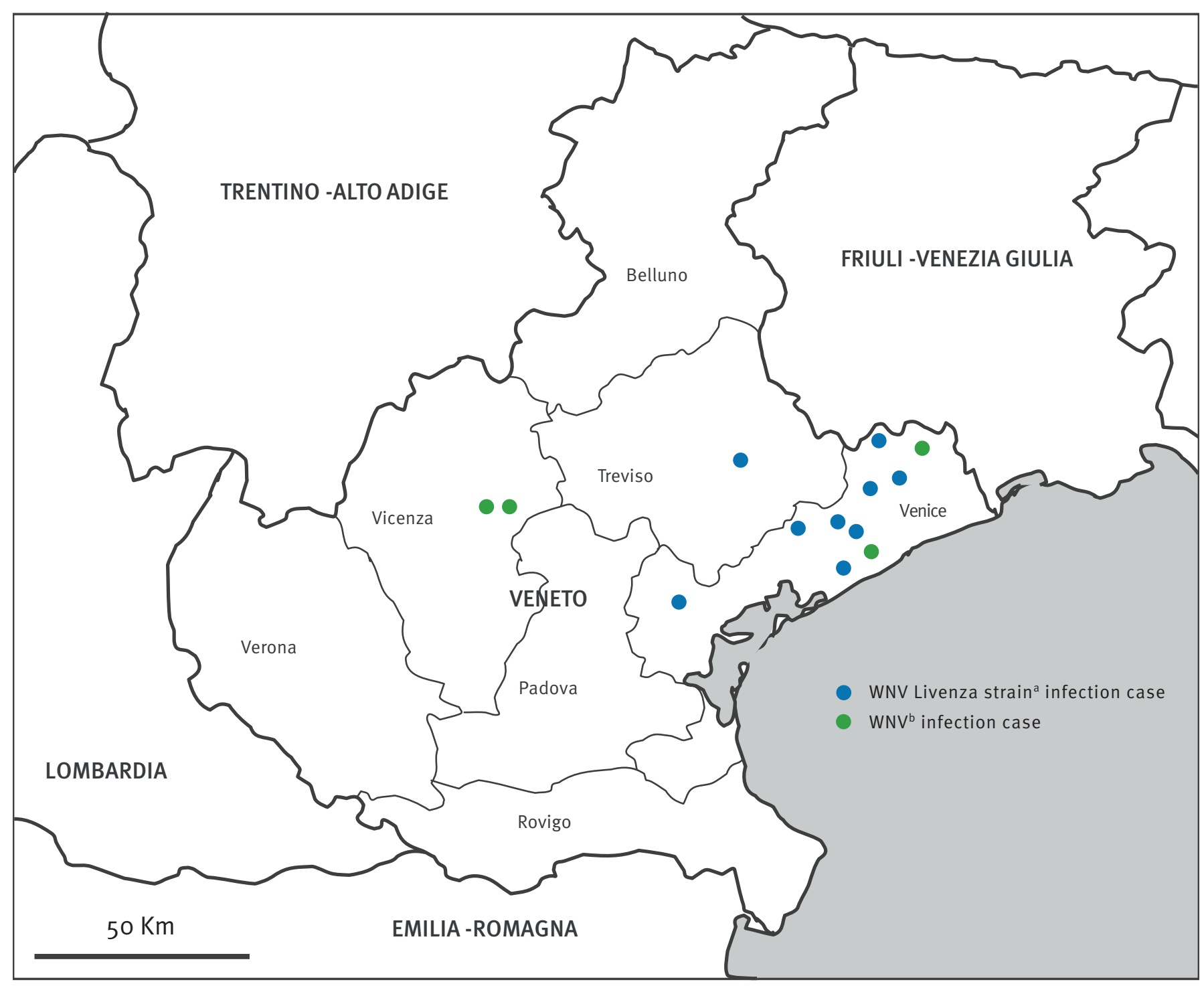

WNV: West Nile virus

a WNV Livenza strain was ascertained by sequencing.

b WNV lineage 1 was confirmed but WNV was not sequenced.

the high viral load in urine allowed sequencing of WNV RNA in most cases.

In conclusion, this study reports an increased WNV activity in northern Italy and describes the clinical presentation of infection with the new endemic WNV Livenza strain, that appears to be responsible for the outbreak.

\section{Funding}

This research was funded by Veneto Region, by the EU (FP7 project WINGS, grant no. 261426), and by the University of Padova (grant no. CPDA108383/10) to Giorgio Palù. 


\section{References}

1. European Centre for Disease Prevention and Control (ECDC) West Nile fever maps. Situation update 23 August 2012. Stockholm: ECDC. [Accessed 29 Aug 2012]. Available from: http://ecdc.europa.eu/en/healthtopics/west_nile_fever/ West-Nile-fever-maps/

2. Centre for Disease Prevention and Control (CDC). 2012 West Nile virus update: as of August 21. [Accessed 29 Aug 2012]. Available from: http://www.cdc.gov/ncidod/dvbid/westnile/ index.htm

3. Barzon L, Pacenti M, Franchin E, Lavezzo E, Martello T, Squarzon L, et al. New endemic West Nile virus lineage 1a in northern Italy, July 2012. Euro Surveill. 2012;17(31):pii=20231. Available from: http://www.eurosurveillance.org/ViewArticle. aspx?Articleld $=20231$

4. Rizzo C, Salcuni P, Nicoletti L, Ciufolini MG, Russo F, Masala R, et al. Epidemiological surveillance of West Nile neuroinvasive diseases in Italy, 2008 to 2011. Euro Surveill. 2012;17(20):pii=20172. Available from: http://www. eurosurveillance.org/ViewArticle. aspx?Articleld $=20172$

5. Barzon L, Pacenti M, Cusinato R, Cattai M, Franchin E, Pagni S, et al. Human cases of West Nile Virus infection in north-eastern Italy, 15 June to 15 November 2010. Euro Surveill. 2011;16(33):pii: 19949. Available from: http://www. eurosurveillance.org/ViewArticle.aspx?Articleld=19949

6. Gobbi F, Barzon L, Capelli G, Angheben A, Pacenti M, Napoletano G, et al. Surveillance for West Nile, dengue, and chikungunya virus infections, Veneto Region, Italy, 2010. Emerg Infect Dis. 2012;18:671-3.

7. European Centre for Disease Prevention and Control (ECDC). EU case definition. Stockholm: ECDC. [Accessed 29 Aug 2012]. Available from: http://ecdc.europa.eu/en/healthtopics/west nile_fever/basic_facts/Pages/EU-case-definition.aspx

8. Barzon L, Pacenti M, Franchin E, Squarzon L, Lavezzo E, Toppo S, et al. Novel West Nile virus lineage 1a full genome sequences from human cases of infection in north-eastern Italy, 2011. Clin Microbiol Infect. 2012. Forthcoming.

9. Lanciotti RS, Kerst AJ, Nasci RS, Godsey MS, Mitchell CJ, Savage HM, et al. Rapid detection of west nile virus from human clinical specimens, field-collected mosquitoes, and avian samples by a TaqMan reverse transcriptase-PCR assay. J Clin Microbiol. 2000;38(11):4066-71.

10. Linke S, Ellerbrok H, Niedrig M, Nitsche A, Pauli G. Detection of West Nile virus lineages 1 and 2 by real-time PCR. J Virol Methods. 2007;146(1-2):355-8.

11. Savini G, Capelli G, Monaco F, Polci A, Russo F, Di Gennaro $A$, et al. Evidence of West Nile virus lineage 2 circulation in Northern Italy. Vet Microbiol. 2012;158(3-4):267-73. 